\title{
Asymmetry, realised volatility and stock return risk estimates
}

\author{
Aurea Grané · Helena Veiga
}

Received: 3 March 2011 / Accepted: 16 March 2012/Published online: 11 April 2012

C) Springer-Verlag 2012

\begin{abstract}
In this paper we estimate minimum capital risk requirements for short and long positions with three investment horizons, using the traditional GARCH model and two other GARCH-type models that incorporate the possibility of asymmetric responses of volatility to price changes. We also address the problem of the extremely high estimated persistence of the GARCH model to generate observed volatility patterns by including realised volatility as an explanatory variable into the model's variance equation. The results suggest that the inclusion of realised volatility improves the GARCH forecastability as well as its ability to calculate accurate minimum capital risk requirements and makes it quite competitive when compared with asymmetric conditional heteroscedastic models such as the GJR and the EGARCH.
\end{abstract}

Keywords Asymmetry $\cdot$ High-frequency data $\cdot$ Minimum capital risk requirements $\cdot$ Realised volatility

JEL Classification $\mathrm{C} 14 \cdot \mathrm{C} 15 \cdot \mathrm{G} 15$

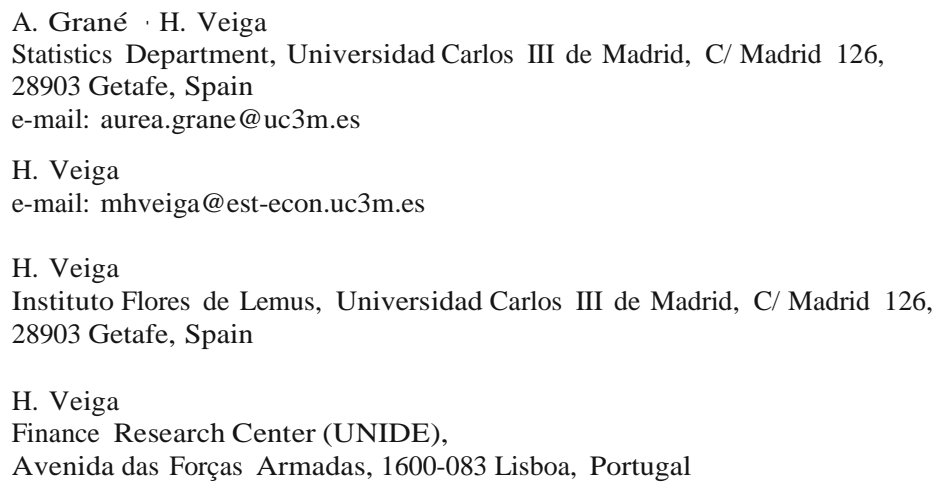

